\title{
NOTAS
}

\section{Consideraciones sobre el sitio arqueológico Marcahuasi de Iris, distrito de San Juan de Iris- Huarochirí: cuenca del río Santa Eulalia}

\author{
Considerations about Marcahuasi de Iris archaeological site, San Juan de \\ Iris-Huarochirí district: Santa Eulalia river basin
}

\author{
Yomira Silvia Huamán Santillán \\ http://orcid.org/0000-0001-5209-9514 \\ Universidad Nacional Mayor de San Marcos \\ yomira.huaman@unmsm.edu.pe
}

\section{INTRODUCCIÓN Y MARCO REFERENCIAL}

El año 2018 como parte del curso de Métodos en Arqueología I a cargo del arqueólogo Daniel Morales Chocano y su ayudante de cátedra Arnold Aguilar, realizamos trabajos de prospección arqueológica en la cuenca alta del río Santa Eulalia, específicamente en la margen izquierda, distrito de San Juan de Iris, provincia de Huarochirí. Por ello, visitamos el sitio arqueológico de Marcahuasi de Iris en las coordenadas UTM (WGS-84): $8706444 \mathrm{~N}, 331828 \mathrm{E}$ y a $3850 \mathrm{~m}$ s. n. m.

Existen pocas investigaciones arqueológicas sobre la provincia Huarochirí, a pesar que estas se iniciaron a comienzo del siglo pasado con los estudios de Julio C. Tello en Marcahuasi de Casta (Tello y Miranda, 1923) y el estudio osteológico y paleopatológico de restos humanos del distrito de Huarochirí (Tello,1909). Tuvo que pasar más de medio siglo para que Alberto Bueno (1992) nos presente una visión global de la arqueología de Huarochirí en la cual describe muchos sitios arqueológicos del Intermedio Tardío en la cuenca del río Santa Eulalia. En el año 2010 Pieter 
van Dalen publica un reporte sobre sistemas agrícolas hidráulicos en la sierra de Lima, describiendo la represa de Antacocha, ubicado en la comunidad campesina de Vicas, distrito de Huachupampa en la cuenca alta del río Santa Eulalia (van Dalen, 2010). Desde inicios del presente siglo Daniel Morales Chocano ha realizado conjuntamente con estudiantes de arqueología de la Universidad Nacional Mayor de San Marcos, reconocimientos sistemáticos en la cuenca del río Santa Eulalia, principalmente en el distrito de San Antonio de Chaclla (Morales,2014); registrando sitios importantes como Chinchilca, Chuyac y Huambo. Alfredo Altamirano (2014) realiza un análisis estructural de las huancas de Puncayan, algunas de las cuales tiene forma zoomorfa. Alfonso Ponciano (2007) realizó un registro detallado del sitio arqueológico tardío de Japaní en el distrito de Carampoma.

Es importante destacar las fuentes etnohistóricas coloniales tempranas que hacen referencia a la organización sociopolítica de la cuenca del río Santa Eulalia. En primer lugar, tenemos la visita realizada en 1586 por el corregidor de Yauyos Diego Dávila Briceño (Dávila, 1881-1897), quien describe que la organización de la provincia Inca de Yauyos estaba formada por cinco parcialidades entre ellas la de Chaclla correspondiente a la cuenca del río Santa Eulalia y Mama al valle medio del río Rímac.

De igual manera en el manuscrito quechua de Huarochirí de Francisco de Ávila escrito en 1622 (Taylor, 1987) se describen en algunos pasajes las costumbres de los Chacllas, señalando que antes de la generalización del culto huarochirano al dios Pariacaca, las poblaciones del río Santa Eulalia adoraban al dios Huallayo Carhuincho. Así mismo señala que el santuario de Mama se hallaba cerca a la confluencia de los ríos Santa Eulalia y Rímac. Muchas de las antiguas tradiciones prehispánicas de estas zonas de Huarochirí se mantienen vigente hasta la actualidad, aunque con algunas variaciones producto del sincretismo religioso, como encontramos en San Juan de Iris la fiesta de la Champeria, del agua o limpia de acequia (Martínez, 2017); o la danza de la Hualina (Rengifo, 2018).

\section{EL SITIO ARQUEOLÓGICO DE MARCAHUASI DE IRIS}

El sitio arqueológico de Marcahuasi de Iris se ubica a $2.33 \mathrm{kms}$ al suroeste del pueblo de San Juan de Iris (en línea recta), siguiendo un camino casi recto que va ascendiendo según la topografía del cerro. El sitio se emplaza en la parte superior del cerro Carahuaque, tanto en la ladera superior como en las dos cimas que coronan el cerro. Estas dos cimas se ubican hacia ambos lados de una explanada baja, en la cual se habilitó una plaza de medianas dimensiones y planta irregular, de aproximadamente $15 \mathrm{~m}$ de diámetro, presentando en sus lados muros perimétricos que en algunos casos cumplen la función de muro de contención de plataformas contiguas. 
Hacia el lado este de esta plaza y con mayor elevación (sobre un promontorio rocoso) se emplaza el sector A conocido también como el sector Hanan o Alto, el cual presenta edificaciones con planta rectangular distribuidos alrededor de patios cuadrangulares y ovalados, pero en mal estado de conservación y cubiertos de densa vegetación arbustivas y cactáceas; situación que hizo complicado el registro arqueológico y la identificación de las edificaciones.

Por su parte el sector B, conocido también como el sector Hurin o bajo, se ubica hacia el lado occidental, se encuentra en mejor estado de conservación, identificándose dos conjuntos arquitectónicos principales. El primer conjunto está conformado por un edificio de tres pisos superpuestos y un patio interior. El basamento de los muros y el paramento en el primer nivel es a base de piedras grandes unidas con argamasa, mientras que en los dos niveles superiores es a base de piedras medianas unidas con barro.

El segundo conjunto del sector B está conformado por siete recintos, algunos interconectados entre sí, asociados a un patio de planta irregular ubicado en el extremo norte del conjunto. Alrededor de estos dos conjuntos se extienden otros conjuntos en mal estado de conservación, los cuales se extienden hasta la cima del promontorio y descienden a la parte posterior. En el conjunto B se aprecia un edificio de planta rectangular con esquinas curvas de hasta cuatro niveles superpuestos y patios en el interior. Los muros del primer nivel están edificados con piedras grandes uniformes unidas con argamasa, mientras que en los niveles superiores hay un cambio en el patrón, pues se utilizaron piedras más pequeñas. Este edificio tiene vanos internos de $0.80 \mathrm{~m}$ de alto y $0.60 \mathrm{~m}$ de ancho, accediendo desde el recinto principal a los recintos secundarios (compartimientos internos). El más representativo de estos compartimientos o recintos en su primer nivel tiene $2.20 \mathrm{~m}$ de largo y $1.20 \mathrm{~m}$ de altura.

Las edificaciones de todo el sitio son a base de piedras canteadas medianas unidas con argamasa, presentando pachillas intermedias para dar mayor estabilidad a los muros. La mayoría de edificaciones son de planta cuadrangular o rectangular, algunas con las esquinas curvas y otras rectas. La altura máxima de estos edificios es de $3.50 \mathrm{~m}$. Los muros tienen un grosor promedio de $0.90 \mathrm{~m}$. Algunos muros se van engrosando en la parte superior para servir de sostén a la cubierta. Estas cubiertas son planas formadas por piedras lajas grandes colocadas una sobre otras y cubiertas con barro; algunas de estas lajas salen del paramento a modo de voladizo.

$\mathrm{Al}$ interior de ambos sectores se puede apreciar edificaciones que cumplen la función de viviendas, pero también estructuras funerarias, de hasta tres niveles superpuestos. Cada uno de estos niveles está dividido por piedras lajas que van articuladas al paramento e incluso presentan voladizos hacia la parte externa. Las viviendas pueden tener hasta dos niveles superpuestos, presentando dos accesos desde el exterior. En general los vanos son medianos, tienen menos de $1 \mathrm{~m}$ de altura y $0.80 \mathrm{~m}$ de ancho. 
En superficie del sitio se aprecia poco material cultural mueble, en especial material cerámico de naturaleza doméstica. También se aprecia algunos batanes. En general el sitio se encuentra en regular estado de conservación, mientras que el área nuclear del sector B presenta las edificaciones en pie y en perfecto estado, las áreas periféricas de este sector, al igual que el sector A se encuentra en mal estado. Muchas edificaciones presentan colapso, erosión basal, forados y fisuras.

Alrededor del sitio arqueológico, en la margen izquierda del río Santa Eulalia, existen extensas áreas de andenes, el mayor porcentaje se encuentran en estado de abandono (Yakabi, 2017). En la parte baja del sitio, hacia la quebrada, se aprecia andenes continuos y escalonados con amplias terrazas, las cuales habrían sido las áreas productivas de la población que vivió en este sitio, al igual que la actividad ganadera.

Este sitio de Marcahuasi de Iris, cuyo nombre arqueológico habría sido Carahuaque, fue la sede de uno de los ayllus más importantes de esta sección del valle del río Santa Eulalia y se habría encontrado en constaste interacciones socioculturales con los pueblos arqueológicos ubicados en el actual distrito de San Pedro

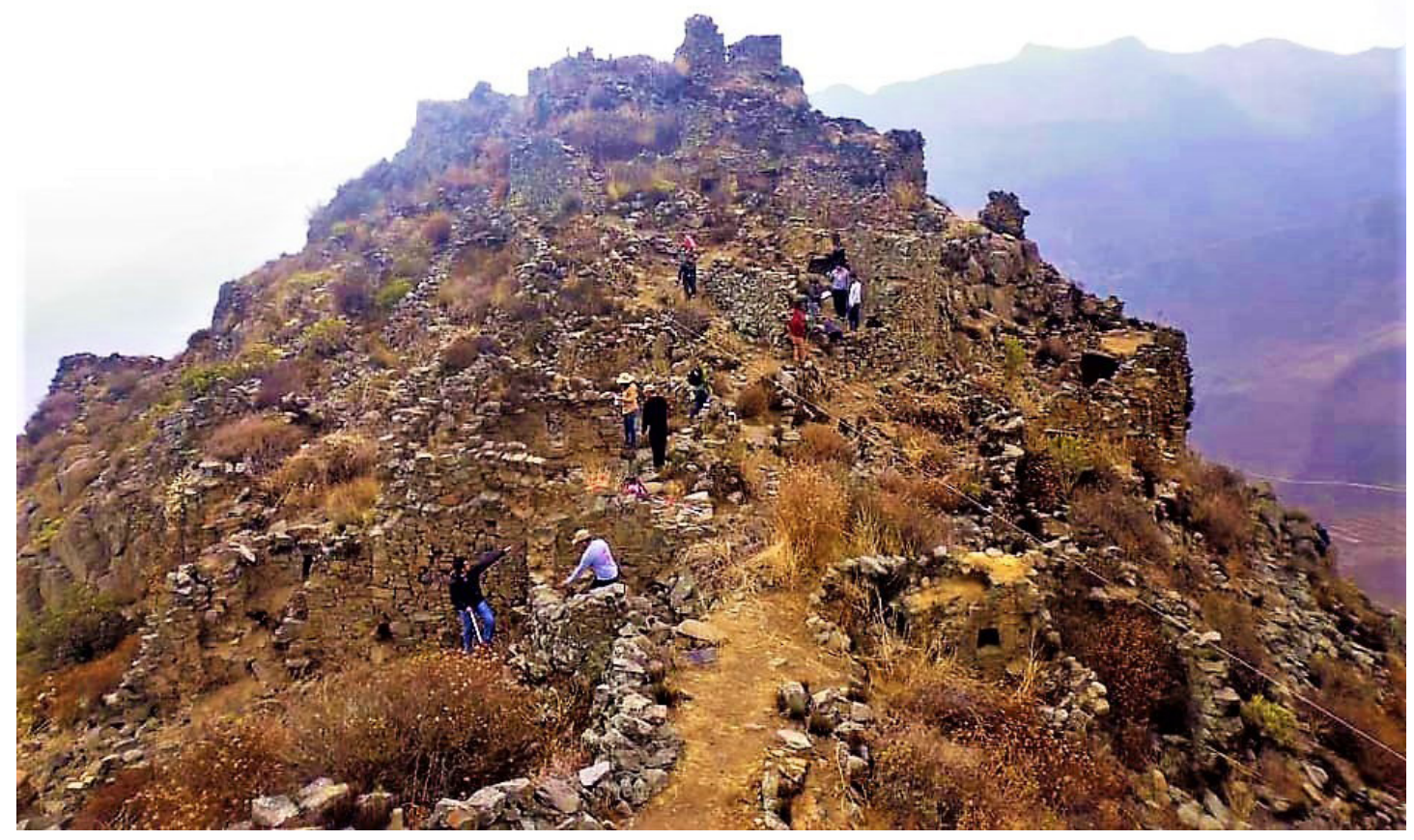

Figura 1. Vista panorámica de los conjuntos arquitectónicos 1 y 2 del sector Hurin en pleno trabajo de prospección. 


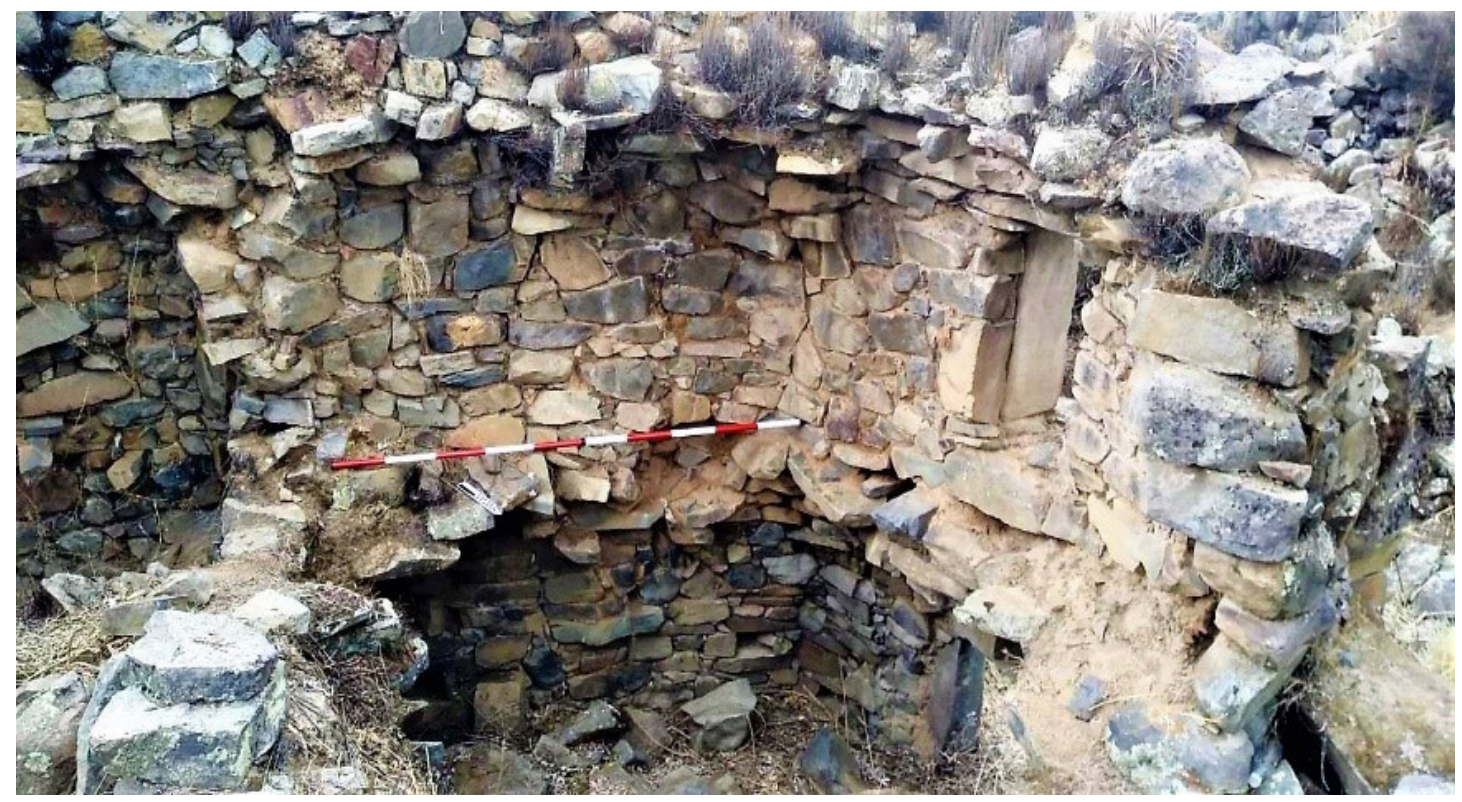

Figura 2. Vista de un recinto habitacional de dos niveles (foto: Nicole Ramírez).

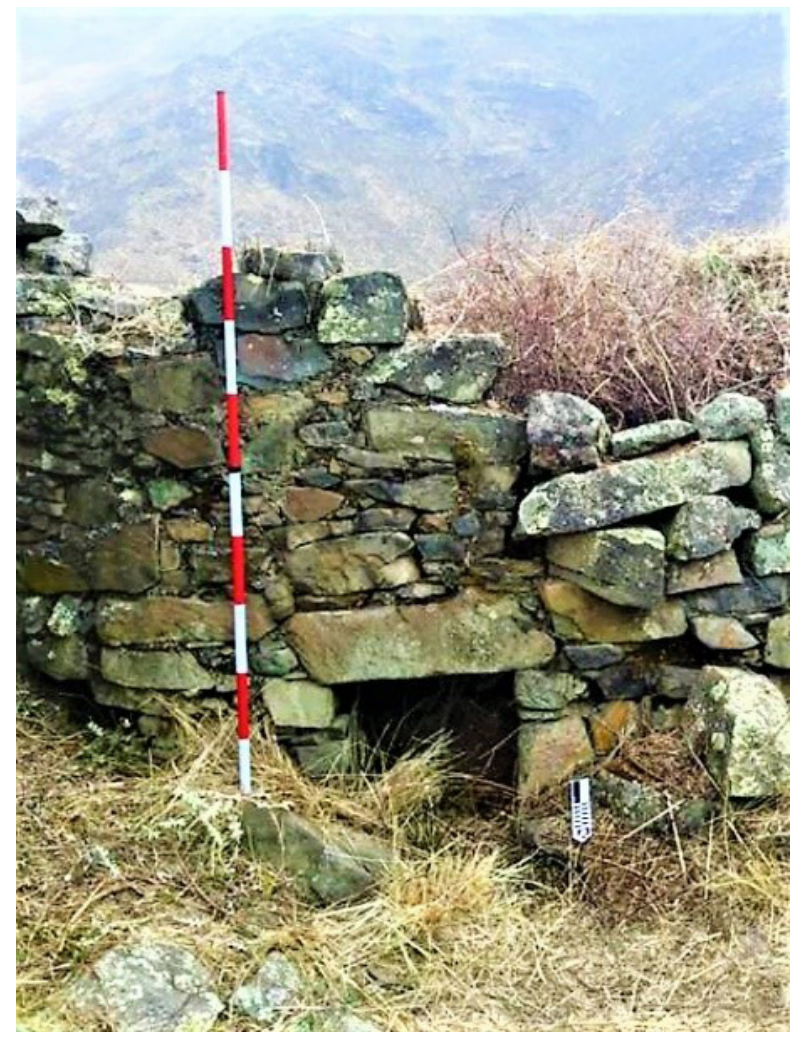

Figura 3. Vista de una estructura funeraria tipo chulpa (foto: Katherine Osores). 
de Casta, como el caso de Marcahuasi. Aun no es posible determinar a que grupo étnico, cultural o sociedad perteneció este poblado de Marcahuasi de Iris; pues hace falta mayores investigaciones arqueológicas territoriales en toda la cuenca de permitan a partir de la recurrencia de patrones culturales, la identificación de los grupos socioculturales que ocuparon estas zonas en periodo prehispánico tardío. Sin embargo, como hipótesis podemos plantear que al territorio de los actuales distritos de San Juan de Iris y San Pedro de Casta como formaron una unidad sociocultural en periodos prehispánicos tardío. Esto es señalado por van Dalen (2014, p. 22) quien señala que los sitios más importantes de los castas se ubicaban en la meseta de Marcahuasi. Futuras investigaciones arqueológicas y etnohistóricas de la zona podrán corroborar esto.

\section{CONCLUSIONES}

En periodos prehispánicos tardíos el sitio arqueológico de Marcahuasi de Iris o Carahuaque, se constituyó, uno de los centros poblados más grandes e importantes de la cuenca del río San Eulalia. El sitio esta conformado por dos sectores (Hanan y Hurin), distribuidos hacia ambos flancos de una gran plaza. Se aprecia en cada uno de estos sectores, áreas de vivienda conformados por recintos de planta cuadrangular (de hasta dos niveles) y estructuras funerarias de plantas cuadrangular (de hasta cuatro niveles).

\section{RECONOCIMIENTOS}

Quiero reconocer al Mg. Daniel Morales Chocano, docente del curso de Métodos en Arqueología I de la UNMSM, quien junto a su ayudante de catedra Arnold Aguilar, nos llevó a conocer el sitio arqueológico. Así mismo quiero reconocer a mis compañeros que participamos en el registro del sitio quienes figuran: Katherine Chacón, Katherine Dulanto, Brany Portillo y Walter Pareja.

\section{REFERENCIAS BIBLIOGRÁFICAS}

Altamirano, A. (2014). De la huanca a lo cognitivo: el sitio arqueológico tardío de Punkayán, distrito de Huachupampa, Huarochirí, Perú. Arqueología de las cuencas alto y medio andinas del departamento de Lima (pp. 257-274). Pieter van Dalen, ed. Lima: Universidad Nacional Mayor de San Marcos.

Bueno, A. (1992). Huarochirí ocho mil años de historia. Huarochirí. Lima, Perú: Municipalidad de Santa Eulalia de Acopaya.

Dávila Briceño, D. (1881. [1586]). Descripción y Relación de la Provincia de Yauyos. Relaciones Geográficas de Indias. Tomo I. Marcos Jiménez de la Espada, ed. Madrid. 
Martínez, F. (2017). Cultura y Sociedad en San Juan de Iris. En: Carlos Llerena, Moshe Inbar y María Benavides (Ed.). Conservación de Andenes. Universidad Nacional Agraria La Molina/ Universidad de Haifa. pp.125-131.

Morales, D. (2014). La prospección arqueológica: Diseño de una propuesta para la sierra de Lima. En Pieter van Dalen, (ed.). Arqueología de las Cuencas alto y medio andinas del departamento de Lima (pp. 275-280). Lima: Universidad Nacional Mayor de San Marcos.

Ponciano, A. (2006). Japani: Tukuy Rikuq, 3, pp. 39-49. Lima: Editorial Grupo Kuntur.

Rengifo de La Cruz, E. (2018). Al canto del agua. Poesía, testimonio y libro de la comunidad andina de San Pedro de Casta, Huarochirí. Huancayo.

Taylor, G. (1987). Ritos y tradiciones de Huarochirí, Lima. Instituto de Estudios Peruano Tello, J. C. (1909). La antigüedad de la sífilis en el Perú.

Tello, J. C. y Miranda, P. (1923). Wallallo y Carhuincho Ceremonia Gentilicia de una comunidad. En J.C. Tello, (Ed.) INCA, revista trimestral de estudios antropológicos, I(4), 510-522.

van Dalen Luna, P. (2010). Sistemas agrícolas e Hidráulicos en la región altoandina del departamento de Lima, provincias de Yauyos y Huarochirí. Boletín de Lima, 161, pp. 47-59. Lima.

van Dalen Luna, P. (2014). El territorio y las investigaciones a modo de introducción al presente libro. Arqueología de las cuencas alto y medio andinas del departamento de Lima (pp. 9-30). Pieter van Dalen, (ed.). Lima: Universidad Nacional Mayor de San Marcos.

Yakabi Bedriñana, K. (2017). Integrando dimensiones para la comprensión del proceso de abandono de los sistemas de andenería de la comunidad campesina San Juan de Iris, subcuenca Santa Eulalia, Huarochirí. Tesis para optar el grado de Magister en desarrollo ambiental. Lima: Pontificia Católica del Perú. 


\section{SOBRE LA AUTORA}

\section{Yomira Silvia Huamán Santillan}

Egresada en Arqueología en la Universidad Nacional Mayor de San Marcos. Dirigió la investigación: "Cajamarquilla, identificación de su máxima extensión a través de la arquitectura del tapial en el Periodo Intermedio Tardío" (E2015007c), proyecto ganador del Programa de Promoción de trabajo de investigación para optar el grado de Bachiller, del Vicerrectorado de Investigación y Posgrado de la Universidad Nacional Mayor de San Marcos. Se desempeñó como arqueóloga de campo y gabinete en el "Proyecto Arqueológico La Huaca". Actualmente se desempeña como jefe de campo en el proyecto "Determinación de las características socioculturales del patrimonio arqueológicos de las comunidades campesinas altoandinas de la provincia de Huaral." Y también como responsable del "Proyecto arqueológico con escuela de campo, Cajamarquilla 2021". 